\title{
Granulomatous Inflammatory Response in a Case of Typhoid Fever
}

\author{
S. Bharadwaj ${ }^{\text {a J.T. Anim }}{ }^{\text {a }}$ F. Ebrahim ${ }^{\text {b }}$ A. Aldahham ${ }^{\text {b }}$

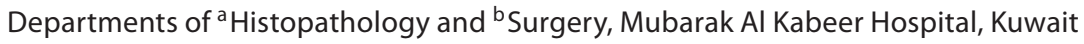

\section{Key Words}

Typhoid fever · Granuloma • lleum • Lymph node

\begin{abstract}
Objective: To present a case of culture-proven typhoid fever in which granulomas were demonstrated histologically in the ileum and mesenteric lymph nodes. Clinical Presentation and Intervention: A 47-year-old Pakistani man underwent emergency hemicolectomy for severe bleeding per rectum associated with diarrhea. Two large ulcers in the ileum, near the ileocolic junction, as well as mesenteric lymph nodes showed both necrotizing and non-necrotizing granulomas in addition to mixed inflammatory infiltrate on histology. Conclusion: Typhoid fever may be considered as one of the causes of the differential diagnoses of granulomatous inflammation of the small intestine.
\end{abstract}

Copyright $\odot 2009$ S. Karger AG, Basel

\section{Introduction}

Typhoid fever is a systemic infectious disease caused by the Gram-negative bacillus Salmonella typhi. Microscopically, typhoid lesions consist predominantly of histiocytes admixed with lymphocytes and plasma cells. Neutrophils are typically inconspicuous. These constitute typhoid nodules which occur in many organs. The altered macrophages or histiocytes phagocytose the ty- phoid bacteria as well as erythrocytes and degenerated lymphocytes. Well-formed granulomas are rare within typhoid lesions [1], including typhoid ulcers in the small intestine. Although granulomas have been described in the bone marrow, liver and spleen in cases of typhoid fever [2-6], to the best of our knowledge, true granulomas have not been described in the primary ulcer in the ileum or mesenteric lymph nodes. We report a case of typhoid fever in which true granulomas were demonstrated in the ileum and mesenteric lymph nodes and discuss these morphological features as well as possible differential diagnoses.

\section{Case Report}

A 47-year-old Pakistani man presented with a 1-week history of fever and a 1-day history of bleeding per rectum with clots and diarrhea. He also complained of fatigue and generalized weakness of 1 week duration. He was on a regular course of non-steroidal anti inflammatory drugs (NSAIDs) for osteoarthritis. On examination, he had low grade fever of $38^{\circ} \mathrm{C}$, and was pale, but his vital parameters were stable. Systemic examination did not reveal any abnormality. Rectal examination confirmed fresh blood with normal anal tone but no hemorrhoids or any other mass. Hematological and biochemical parameters including coagulation profile were normal except reduced hemoglobin $(10.8 \mathrm{~g} / \mathrm{l})$. Samples of blood, urine and stool were taken for bacterial culture.

While on admission, he bled profusely along with the loose stools. His hemoglobin dropped further to $7.3 \mathrm{~g} / \mathrm{l}$ and then to $6 \mathrm{~g} / \mathrm{l}$ within a period of $48 \mathrm{~h}$. Emergency exploratory laparotomy was performed. An inflamed terminal ileum pointed to the

\section{KARGER}

Fax +41613061234 E-Mail karger@karger.ch www.karger.com
(C) 2009 S. Karger AG, Basel

$1011-7571 / 09 / 0183-0239 \$ 26.00 / 0$

Accessible online at:

www.karger.com/mpp
Dr. Shashi Bharadwaj

Department of Histopathology

Mubarak Al Kabeer Hospital

PO Box 43787, Jabriya (Kuwait)

Tel. +965 531 2700, ext. 2188, E-Mail shashi.dhawan@gmail.com 


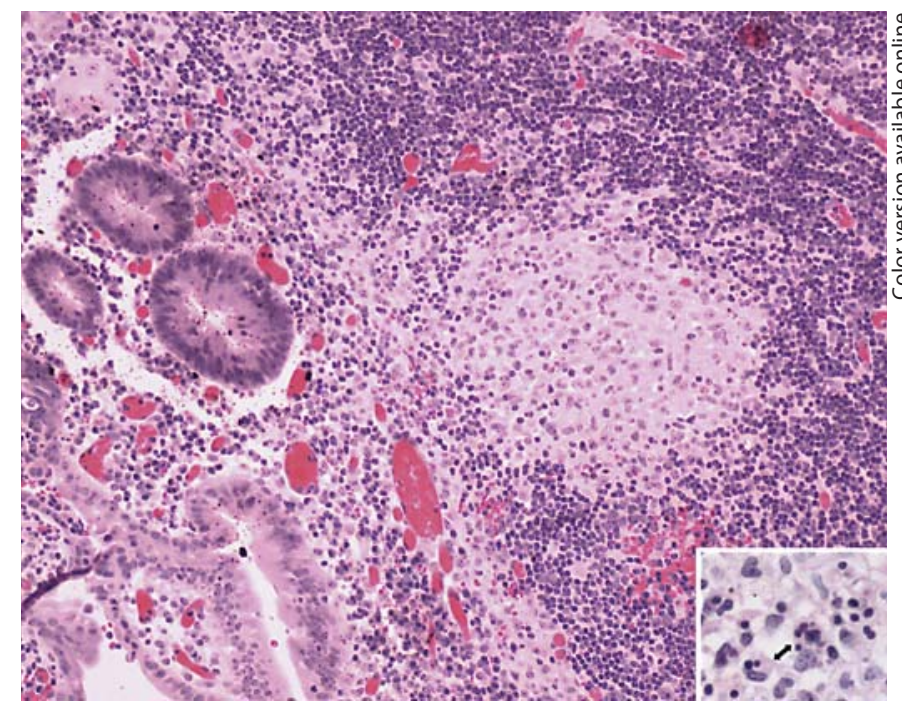

Fig. 1. Photomicrograph of ileal mucosa showing a non-caseating granuloma within the lamina propria. HE. $\times 100$. Inset shows histiocytes with erythro- and lymphophagocytosis (arrows). HE. $\times 400$.

source of the gastrointestinal bleeding, and right hemicolectomy was performed after blood transfusion. The hemicolectomy specimen showed two large ulcers in the ileum near the ileocolic junction. The larger ulcer was $3 \times 2 \mathrm{~cm}$, while the smaller one measured $2.5 \times 2 \mathrm{~cm}$. The ulcers had irregular margins and did not show any particular orientation. There was no significant thickening of the ileal wall. The rest of the small intestinal and colonic mucosa was edematous. There was no perforation. Representative sections from the ulcer and terminal ileum showed extensive mucosal ulceration and transmural mixed inflammatory infiltrate. The base of the ulcer showed necrosis and neutrophilic exudate. Many non-necrotizing granulomas were also seen in the tissue surrounding the ulcer.

Sections from the four mesenteric lymph nodes in the specimen showed extensive necrosis with surrounding sheets of histiocytes and focally preserved lymphoid architecture. Careful search showed occasional lympho- and erythrophagocytosis both in ileal lesions and lymph nodes (fig. 1). In addition, there were many well-formed granulomas in the lymph nodes, showing giant cells (fig. 2). Some granulomas also showed neutrophilic abscesses in the centre. Ziehl-Neelsen (Z-N) stain did not reveal acid-fast bacilli. However, modified Gram's stain (Brown and Hopp) showed numerous Gram-negative bacilli, both intracellularly within the histiocytes and extracellularly, including the necrotic areas. Differential diagnoses of yersiniosis, Crohn's disease with secondary bacterial infection, and salmonellosis, considered. Serology for $S$. typhi, i.e. Poly $\mathrm{H}$ and $\mathrm{Vi}$ antigens, was positive, but serology for Yersinia was negative. Blood culture later grew S. typhi, which was further confirmed by the Vitek II and API 20 tests. Culture for mycobacteria could not be performed as the tissue had been fixed in formalin for more than $24 \mathrm{~h}$. The patient recovered completely after appropriate antibiotic therapy for typhoid fever.

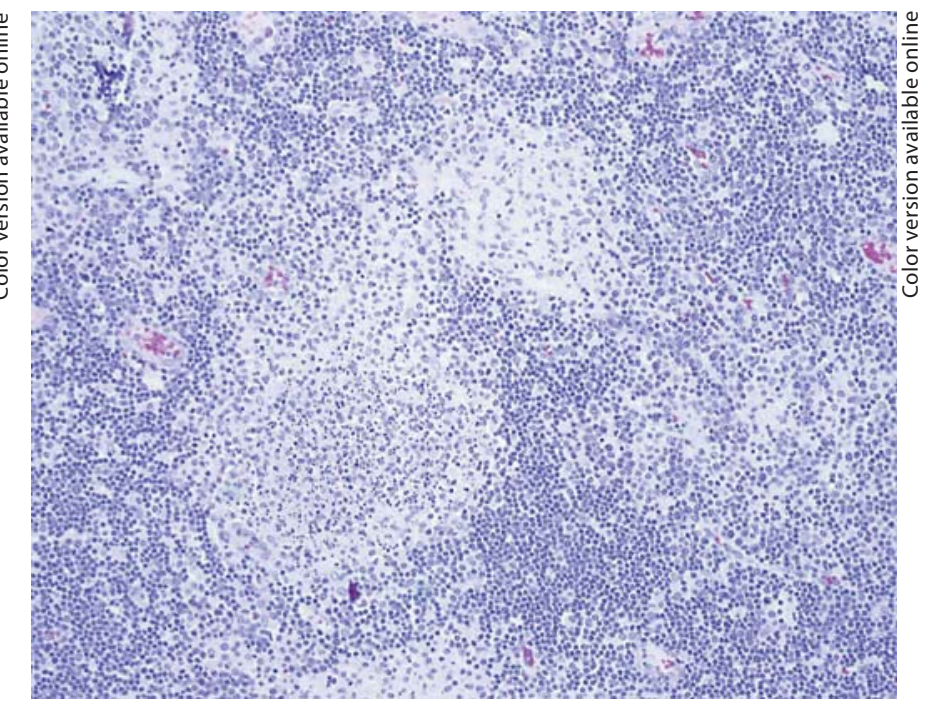

Fig. 2. Photomicrograph of mesenteric lymph node showing granuloma with multinucleated giant cells. HE. $\times 400$.

\section{Discussion}

The usual histological findings in typhoid ulcer are necrosis and histiocytic proliferation with prominent erythro- and lymphophagocytosis. Granulomatous inflammation is an unusual histopathological presentation [1]. When it occurs, granulomas are described in sites other than the primary intestinal ulcer. Only 5 cases of typhoid fever with hepatic granulomas have been reported in the English language literature [2-4]. Paris [2] reported 5 cases of typhoid hepatitis, out of which 2 revealed hepatic granulomas. Satti et al. [3] reported a series of 59 patients with hepatic granulomas, the etiology of which was typhoid fever in only one. That patient had fever, hemoptysis and hepatomegaly, raising the suspicion of tuberculosis, but the results of serology were consistent with typhoid fever. Liver biopsy revealed noncaseating granulomas of loose texture. The patient improved rapidly with the treatment of typhoid fever. Mert et al. [4] also reported a case with splenic granuloma and another case with bone marrow granuloma in addition to hepatic granuloma.

A few other cases demonstrating the association of typhoid fever with bone marrow granulomas have been reported [5-7]. Granulomas of the bone marrow in typhoid fever were well described in 27 cases in Korea by Lee et al. [8]. In their typhoid fever cases, well-formed granu- 
loma was seen in $57 \%$ and ill-defined granuloma in $43 \%$. These proportions are similar to the cases studied by Shin et al. [9]. Wain et al. [10], however, did not find granulomas in any of their 37 cases. Lee et al. [8] also compared the granulomas of typhoid fever with those of tuberculosis. In their cases, caseous necrosis and Langhans giant cells were found only in granulomas of tuberculosis, while nuclear debris and phagocytosis were more frequently found in well-formed granulomas of typhoid fever. Our case, however, showed both necrotizing and non-necrotizing granulomas with multinucleated giant cells. Some granulomas also had neutrophilic microabscesses in the center. Though histiocytes were prominent, erythro- and lymphophagocytosis were seen only after prolonged search.

In view of the peculiar histological features of our case, dual infection due to salmonella and mycobacteria may also be considered. This is more likely on the Indian subcontinent where the prevalence of both diseases is very high. However, in our case the acute presentation leading to lower gastrointestinal bleeding and the short history of fever supported the diagnosis of salmonellosis, which was later confirmed by both serology and blood culture. The Z-N stain was also negative, and although culture for mycobacteria could not be done, complete recovery following treatment of typhoid fever would support the fact that these changes were due to S. typhi alone.

It has become increasingly clear that NSAIDs cause damage not only to the upper gastrointestinal tract but also to the small and large intestine. In rare cases, some will show granulomatous change [11]. Our patient was on NSAIDs for a long duration. However, histopathology showed numerous bacilli within the epithelioid cells and giant cells of these granulomas in addition to confirmatory serological and culture tests for S. typhi.

\section{Conclusion}

This case highlighted the need to include other special stains like modified Gram's stain in the usual panel of special stains (Z-N stain, stains for fungus, etc.) which are performed in the investigation of tissues showing granulomatous inflammation. Since blood culture is positive only in $60-80 \%$ of cases of typhoid fever and serology is not absolutely specific, by performing such simple stains surgical pathologists can give useful clues to the diagnosis. We recommend that $S$. typhi be also considered as one of the etiological agents in granulomatous inflammation in various organs.

\section{References}

1 Lamps LW: Infective disorders of the gastrointestinal tract. Histopathology 2007;50:5563.

2 Paris P: Hepatitis-like picture in typhoid fever. BMJ 1984;289:225-226.

-3 Satti MB, al- Freihi H, Ibrahim EM, AbuMelha A, al-Ghassab G, al-Idrissi HY: Hepatic granulomas in Saudi Arabia: a clinicopathological study of 59 cases. Am J Gastroenterol 1990;85:669-674.

4 Mert A, Tabak F, Ozaras R, Ozturk R, Hilal A, Yildirim A: Typhoid fever as a rare cause of hepatic, splenic and bone marrow granulomas. Int Med 2004;43:436-439.
5 Frish B: Biopsy Pathology of Bone and Bone Marrow. London, Chapman and Hall, 1985, pp 58-69.

6 6 Eid A, Carion W, Nystrom JS: Differential diagnoses of bone marrow granuloma. West J Med 1996;164:510-515.

7 Jin SY, Le KW, Kim TS: A study on the typhoid granuloma in the bone marrow biopsy of patients with typhoid fever. Kor J Pathol 1986;20:462-469.

8 Lee JH, Lee YH, Ahn SH, Choi HS: Granulomatous bone marrow disease - a review of the hematopathologic analysis of 27 cases. Kor J Clin Pathol 1985;5:515-521. $\checkmark 9$ Shin BM, Paik IK, Cho HI: Bone marrow pathology of culture proven typhoid fever. J Kor Med Sci 1994;9:57-63.

10 Wain J, Bay PVB, Vinh H, Duong NM, Diep TS, Walsh AL, Parry CM, Hasserjian RP, Ho VA, Hien TT, Farrar J, White NJ, Day NPJ: Quantization of bacteria in bone marrow from patients with typhoid fever: relationship between counts and clinical features. J Clin Microbiol 2001;39:1571-1576.

11 Baert F, Hart J, Blackstone MO: A case of diclofenac induced colitis with focal granulomatous change. Am J Gastroenterol 1995;90: 1871-1873. 